\title{
Efeito de um extrato de Hipérico (Hypericum perforatum) na marcação in vitro de elementos sangüíneos com tecnécio-99m e na biodisponibilidade do radiofármaco pertecnetato de sódio em ratos Wistar
}

\author{
Sebastião David Santos-Filho², Mario Bernardo-Filho ${ }^{3}$
}

\begin{abstract}
Santos-Filho SD, Bernardo-Filho M. Efeito de um extrato de Hipérico (Hypericum perforatum) na marcação in vitro de elementos sangüíneos com tecnécio-99m e na biodisponibilidade do radiofármaco pertecnetato de sódio em ratos Wistar. Acta Cir Bras [serial on line] Available from: URL: htt://www.scielo.br/acb.
\end{abstract}

RESUMO - Objetivo: Avaliar o efeito de um extrato de hipérico (Hypericum perforatum) na marcação de elementos sanguíneos com tecnécio-99m (99mTc) e na biodisponibilidade do radiofármaco pertecnetato de sódio em ratos Wistar. Métodos: Sangue (heparinizado) de ratos Wistar é incubado com um extrato de hipérico, com cloreto estanoso e a seguir com Tc-99m, como pertecnetato de sódio ( $99 \mathrm{mTcO}$ Na). Plasma (P) e células (CS) são isolados por centrifugação. Amostras de P e CS também são precipitadas com ácido tricloroacêtico 5\%, e separadas as frações solúveis (FS-P e FS-CS) e insolúveis (FI-P e FI-CS). Para a análise da biodistribuição, 0,3 $\mathrm{mL}$ do radiofármaco $99 \mathrm{mTcO} \mathrm{Na}$ foi administrada em ratos Wistar que receberam por gavagem extrato ou salina $(\mathrm{NaCl} 0,9 \%)$ por 15 dias. Após 10 minutos os animais foram sacrificados e os órgãos isolados para contagem da atividade radioativa. Resultados: O extrato de hipérico reduziu de forma significativa $(\mathrm{P}<0,05)$ a \% ATI ligada às células, à fração insolúvel celular e à fração insolúvel do plasma. A biodistribuição foi diminuída significativamente $(\mathrm{P}<0,01)$ no osso, no músculo e na tireóide. No pâncreas o percentual de radioatividade aumentou significativamente $(\mathrm{P}<0,05)$. Conclusão: No extrato vegetal estudado podem existir substâncias que oxidariam o íon estanoso, reduzindo a fixação do $99 \mathrm{mTc}$ às hemácias e proteínas plasmáticas e celulares. Da mesma forma poderiam produzir alterações metabólicas com conseqüente influência na captação do radiofármaco pertecnetato de sódio no osso, músculo, pâncreas e tireóide.

DESCRITORES: Hipérico. Tecnécio-99m. Biodisponibilidade. Cirurgia.

\section{Introdução}

Hemácias podem ser marcadas com tecnécio-99m (99mTc) e empregadas em diagnóstico por imagem de sangramentos internos, localização de hemangiomas e de obstruções no sistema circulatório que necessitariam de intervenção cirúrgica ${ }^{1,2,3}$. Essas hemácias marcadas também têm sido de importância em vários estudos clínicos e também experimentais de possível interesse para a pesquisa na medicina nuclear ${ }^{4-11}$. Essa marcação é baseada na capacidade de redução do cloreto estanoso $(\mathrm{SnCl})$ que atua sobre o $99 \mathrm{mTc}$, na forma de pertecnetato de sódio. Tem sido descrito que vários fatores interferem na marcação de hemácias e proteínas plasmáticas com $99 \mathrm{mTc}$, e dentre eles estão os produtos naturais ${ }^{8,10,12,13}$.

O radiofármaco pertecnetato de sódio é distribuído através dos líquidos vasculares e intersticiais e apresenta normalmente uma captação preferencial na tiróide, o estômago, trato intestinal, e glândulas salivares ${ }^{14}$. Vários fatores, como a terapia com drogas, a terapia com radiação, processos cirúrgicos, condições de dieta, além de doenças podem afetar a biodistribuição dos diferentes radiofármacos ${ }^{9,16-19}$. Esses fatores levam a uma repetição do exame, resultando numa irradiação desnecessária ao paciente.
Plantas medicinais têm sido utilizadas largamente no mundo no tratamento de doenças, ou mesmo visando potencializar as ações terapêuticas, diminuindo doses e efeitos adversos. Muitos dos efeitos adversos e interações potenciais destas plantas são pouco estudados, assim como grande parte das aplicações médicas e populares é difícil de ser interpretada cientificamente $^{19}$.

A erva de São João (hipérico; Hypericum perforatum) tem suas ações descritas como sedativa, adstringente e diurética, sendo também útil para afecções nervosas com depressão, hemorragias, diarréia e problemas urinários crônicos ${ }^{20}$. Também tem sido sugerida para tratar danos espinhais e é usada para contusões, feridas, tumores e ulcerações. Hypericum perforatum parece ter uma significante atividade antidepressiva tendo sido proposto ser o melhor indicador de estresse clínico do que estresse agudo, e pode indicar atividade adaptogênica ${ }^{2 \mathrm{~T}}$.

O objetivo deste trabalho é avaliar o efeito de extrato de hipérico (Hypericum perforatum) na marcação de elementos sanguíneos com tecnécio-99m e na biodistribuição do radiofármaco pertecnetato de sódio em ratos Wistar.

1. Laboratório de Radiofarmácia Experimental, Departamento de Biofísica e Biometria, Instituto de Biologia Roberto Alcantara Gomes, Universidade do Estado do Rio de Janeiro.

2. Doutorando do Programa de Pós-Graduação em Ciências da Saúde da Universidade Federal do Rio Grande do Norte.

3. Professor Titular, Laboratório de Radiofarmácia Experimental, Departamento de Biofísica e Biometria, Instituto de Biologia Roberto Alcantara Gomes, Universidade do Estado do Rio de Janeiro. 


\section{Métodos}

Sangue foi colhido de ratos Wistar (17 animais) machos, com peso de $336 \pm 11 \mathrm{~g}$, após injeção intraperitoneal com pentobarbital PA na dose de $50 \mathrm{mg} / \mathrm{kg}$ de peso. Amostras de $3 \mathrm{~mL}$ de sangue foram retiradas por punção cardíaca, em seringas com anticoagulante $(0,2 \mathrm{~mL}$ de heparina). Após a coleta de sangue os ratos foram separados para serem novamente manipulados passados 15 a 20 dias. Isto é importante para prevenir infecções e reduzir o estresse e sofrimento dos animais.

Para preparar o extrato, hipérico em pó (Herbarium, Brasil, lote 954661, validade: 08/2006, data de fabricação: 23/04/2002) foi misturado com salina $(\mathrm{NaCl} 0,9 \%)$ na concentração final de $50 \mathrm{mg} / \mathrm{mL}$ e homogeneizado em agitador tipo vortex por 30 segundos. Após filtração, essa solução do extrato foi denominada $100 \%$, sendo diluído para as concentrações de: 6,25 ; 12,$5 ; 25,50$ e $100 \%$ (estudos de marcação de constituintes sanguíneos) que foram usadas nos estudos in vitro e $100 \%$ no estudo in vivo (biodisponibilidade).

Os experimentos (total de 3) de marcação dos constituintes sanguíneos foram realizados em triplicata, havendo a necessidade de um total de $9 \mathrm{~mL}$ de sangue que foram obtidos de um pool de sangue coletado de 3 animais. Amostras de $0,5 \mathrm{ml}$ de sangue foram incubadas, a temperatura ambiente, com o extrato vegetal $(100 \mathrm{iL})$ em diferentes concentrações $(6,25$; 12,$5 ; 25 ; 50$ e $100 \%$ ), por uma hora. Após, foi adicionado 0,5 $\mathrm{mL}$ de solução de cloreto estanoso $(\mathrm{SnCl} ; 1,2 \mathrm{mg} / \mathrm{mL}$; Reagen S.A., Brasil) e realizou-se a incubação por mais uma hora. Após, foram adicionadas $0,1 \mathrm{~mL}$ de $99 \mathrm{mTc}(3,7 \mathrm{MBq})$ na forma de pertecnetato de sódio ( $99 \mathrm{mTcO} \mathrm{Na})$, em todos os tubos, continuando a incubação por mais 10 minutos. As amostras foram centrifugadas ( $1500 \mathrm{rpm}, 5$ minutos) em centrífuga clínica Alpha ICA (Instrumentos Científicos Alpha Ltda.). Alíquotas de plasma (P) e células (C) foram então separadas e a porcentagem de atividades (\% ATI) calculada. Para avaliar o efeito na ligação do Tc-99m às proteínas plasmáticas e celulares, alíquotas de P e C (20 mL) foram também precipitadas em $1 \mathrm{ml}$ de ácido tricloroacético (TCA 5\%), sendo então, centrifugadas e isoladas a fração solúvel (FS) e insolúvel (FI) de $\mathrm{P}$ e C. No controle foi adicionada solução salina no lugar do extrato vegetal. A porcentagem de radioatividade incorporada aos elementos sanguíneos foi calculada.

Nos experimentos de biodisponibilidade (in vivo), um extrato de hipérico $100 \%(50 \mathrm{mg} / \mathrm{mL})$ foi administrado por gavagem em ratos Wistar (5 ratos), com intervalos de 24 horas, entre cada dose por 15 dias. Nos animais controle ( 3 ratos), foi administrada salina. Uma hora após a última dose ( $15^{\circ}$. dia), $0,3 \mathrm{ml}$ do radiofármaco pertecnetato de sódio $(7,4 \mathrm{MBq})$ é injetado através do plexo venoso orbital. Após 10 minutos os animais foram sacrificados e os órgãos isolados para contagem da atividade radioativa em cintilador sólido de $\mathrm{NaI}(\mathrm{Tl})$ (Automatic Gamma Counter, modelo C 5002, Packard, Canadá). A seguir foram calculadas: (i) as percentagens de radioatividade total (\%ATI) nos órgãos e (ii) as percentagens de radioatividade por grama de tecido (\%ATI/g) em cada órgão. As \%ATI/g foram determinadas dividindo-se as percentagens de radioatividade por grama de tecido pela massa de cada órgão.

Os valores experimentais obtidos foram comparados com os resultados do grupo controle usando o teste ANOVA seguido pelo teste de comparações múltiplas de Dunnett.

\section{Resultados}

Na Figura 1 é mostrada a distribuição de radioatividade nos compartimentos celular (C) e plasmático $(\mathrm{P})$ e nas frações insolúvel e solúvel celular e plasmática de amostras de sangue tratadas com diferentes concentrações de extrato aquoso de hipérico $(6,25,12,5,25,50$ e 100\%). Os resultados mostram que o extrato de hipérico reduziu de forma significativa $(\mathrm{P}<0,05)$ a \%ATI ligada às células de 95,03 $\pm 0,51$ (controle) para $4,16 \pm 0,92$ (100\% do extrato), à fração insolúvel celular de $87,46 \pm 5,07$ (controle) para 14,82 $\pm 0,61$ ( $100 \%$ do extrato) e à fração insolúvel do plasma de 76,24 $\pm 6,15$ (controle) para $26,67 \pm 1,70$ ( $100 \%$ do extrato).

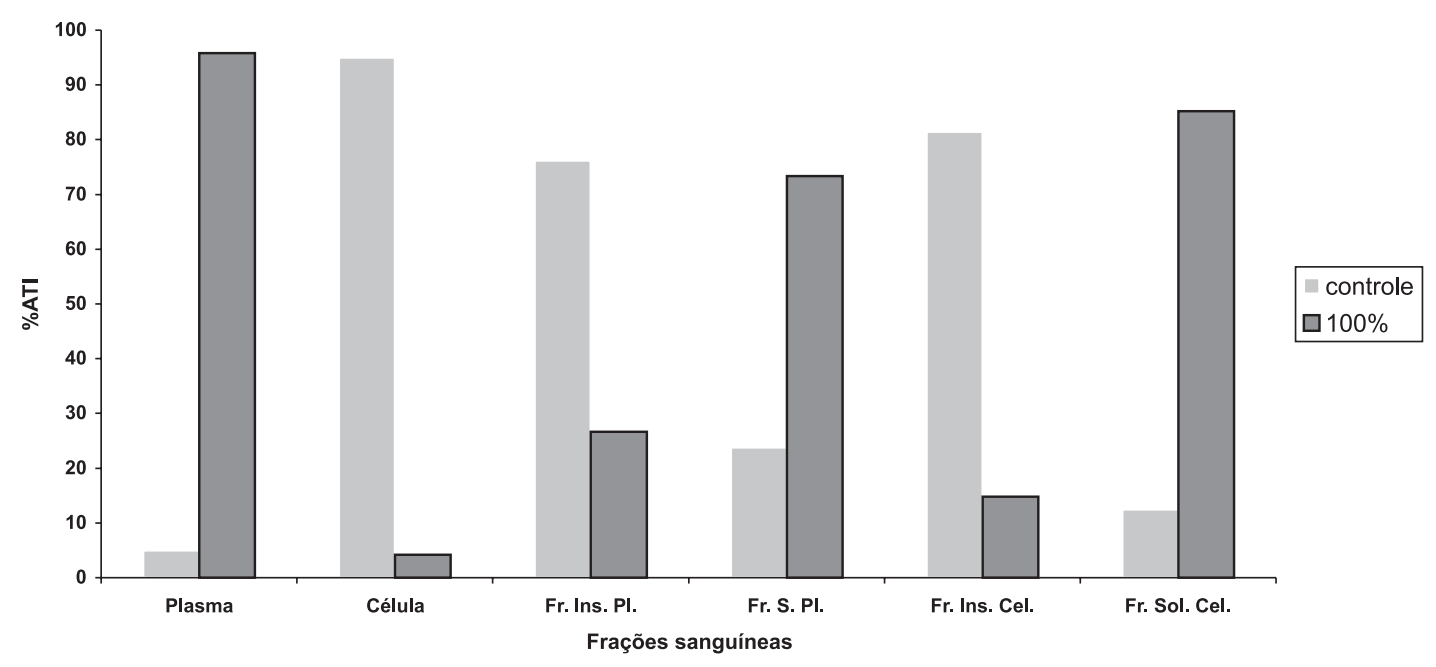

FIGURA 1 - Distribuição de radioatividade nas frações sangüíneas de amostras de sangue tratadas com diversas concentrações de um extrato de hipérico 
Amostras de sangue foram obtidas de ratos Wistar através de punção cardíaca e incubadas in vitro durante uma hora com diferentes concentrações do extrato de hortelã (macerado - folhas e caule) $(100 ; 50 ; 25 ; 12,5 ; 6,25 \%)$. No controle foi utilizada solução salina $0,9 \%$. A seguir foi adicionado cloreto estanoso e Tc-99m. Após centrifugação, amostras de célula (C) e Plasma (P) foram isoladas e também precipitadas com TCA $5 \%$. As amostras foram contadas em cintilador sólido e as \%ATI calculadas.

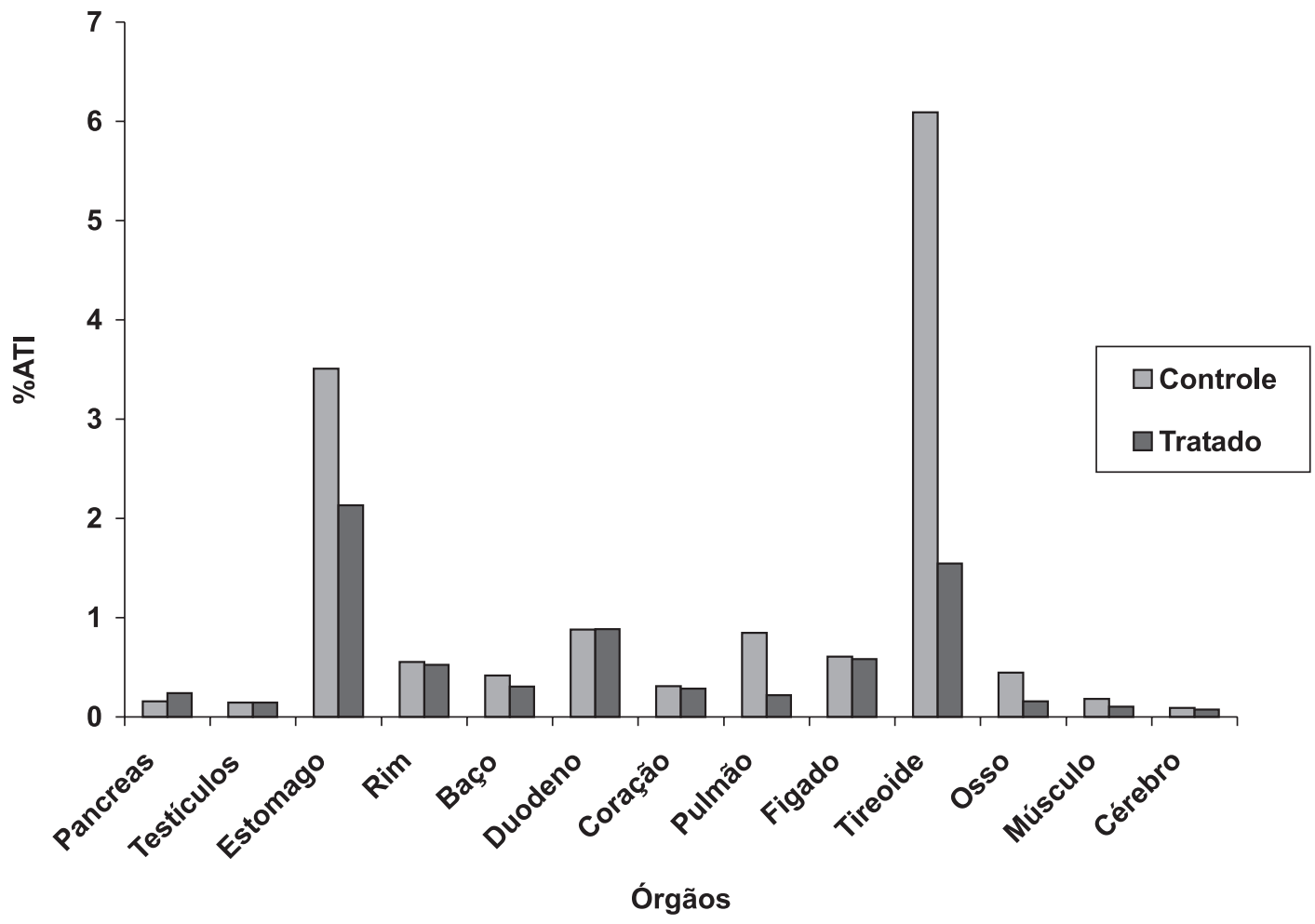

FIGURA 2 - Distribuição da radioatividade do radiofármaco pertecnetato de sódio

Extrato de hipérico $100 \%(50 \mathrm{mg} / \mathrm{mL})$ foi administrado por gavagem em ratos Wistar $(n=5)$, com intervalos de 24 horas, entre cada dose por 15 dias. Uma hora após a última dose (15 . dia), 0,3ml do radiofármaco $(7,4 \mathrm{MBq})$ foi injetado através do plexo venoso orbital. Após 30 minutos os animais foram sacrificados, a contagem da atividade radioativa em cada órgão isolado obtida e foram calculadas as percentagens de radioatividade (\% ATI) nos órgãos.

\section{Discussão}

A marcação de constituintes sanguíneos com 99mTc tem muitas aplicações. Tem sido descrito que extratos obtidos de plantas medicinais podem alterar a marcação de elementos sanguíneos com 99mTc e também a morfologia dos eritrócitos ${ }_{6,7,10,13}$.

A distribuição, a fixxação e a eliminação de radiofármacos em um organismo dependem de vários fatores, tais como o fluxo sanguíneo, o metabolismo tecidual e a ligação aos elementos
Na Figura 2 são mostrados os percentuais de radioatividade por grama dos órgãos retirados de animais tratados com hipérico ou com solução salina (controle). Como pode ser observado alguns órgãos tiveram a biodistribuição diminuída significativamente $(\mathrm{P}<0,01)$ : (a) no osso de $0,45 \pm 0,01$ para $0,16 \pm 0,06$; (b) no músculo de $0,18 \pm 0,004$ para $0,10 \pm 0,02$; (c) na tireóide de $6,09 \pm 1,66$ para $1,54 \pm 1,07$. No pâncreas o percentual de radioatividade aumentou significativamente $(\mathrm{P}<0,05)$ de $0,16 \pm 0,04$ para $0,24 \pm 0,03$. sanguíneos $^{4,15}$. Vários autores têm demonstrado que a biodisponibilidade de radiofármacos pode ser modificado por produtos naturais e sintéticos ${ }^{6-13,22}$.

Nos resultados apresentados na figura 1, o extrato de hipérico foi capaz de diminuir a marcação de constituintes celulares com $99 \mathrm{mTc}$ e nesse processo de marcação tanto os íons estanoso e pertecnetato parecem atravessar a membrana eritrocitária $^{23}$. Seria altamente sugestivo que os produtos existentes no extrato de hipérico poderiam comprometer o trânsito desses íons através da membrana através de proposta apresentada por Krishtal em outro tipo celular ${ }^{24}$. Esses autores descreveram que a hiperforina e outros constituintes do hipérico têm a capacidade de modular canais iônicos da membrana celular. Em relação aos canais de cálcio esse efeito seria devido a interação com a calmodulina ou através das vias de ativação da calmodulina. à ação da hiperforina.s e plasmáticos do sangue.

O extrato de hipérico usado (ver figura 2) diminuiu a captação do 99mTcO Na no osso, no músculo e na tireóide, assim como, aumentou a fixação desse radiofármaco no pâncreas. Esses 
resultados poderiam, em parte, serem atribuídos à capacidade de interação dos produtos presentes no hipérico à membranas lipídicas como descrito por Neagoe ${ }^{25}$. Esses autores têm demonstrado que os componentes de um extrato etanólico de hipérico seriam capaz de interagir com membranas lipídicas acarretando alterações na absorção e biodisponibilidade, assim como efeitos farmacodinâmicos na excitabilidade neuronal.

Na técnica de marcação dos constituintes sanguíneos com 99mTc é necessário um agente redutor. Uma vez que ocorreu redução da marcação dos constituintes sanguíneos com $99 \mathrm{mTc}$, poderia ser especulado que os produtos existentes no extrato de hipérico estariam oxidando o íon estanoso impedindo sua ação. Os compostos químicos presentes nesse extrato também poderiam atuar com agentes quelantes levando à formação de complexos com o $99 \mathrm{mTcO} \mathrm{Na}$ e $\mathrm{SnCl}$, sendo que esse fato também poderia justificar a diminui ção na fixação de radioatividade nos elementos sanguíneos. Possíveis alterações morfológicas promovidas pelo extrato do hipérico, à semelhança às observadas nos estudos com a hortelã ${ }^{13}$ poderiam também justificar a não captação pelas células vermelhas do sangue.

A evidência que um extrato de hipérico pode alterar a marcação de células vermelhas do sangue, assim como a biodisponibilidade de radiofármaco pode ser de grande relevância no momento da interpretação de imagens cintilográficas. Por outro lado, deve-se considerar que os achados experimentais obtidos nesse trabalho foram em condições experimentais controladas e realizadas com ratos.

\section{Conclusão}

De acordo com os resultados obtidos nesse estudo pode-se especular que o extrato de hipérico seria capaz de alterar in vitro a marcação de elementos sanguíneos com 99mTc, assim como também a biodistribuição do radiofármaco 99mTcO Na. A ação biológica desse extrato poderia estar relacionada ${ }^{4}$ (i) propriedades redox do extrato, (ii) efeitos quelantes, (iii) alterações na morfologia das hemácias, (iii) modificação no transporte de íons através da membrana eritrocitária, (iv) metabolização no organismo e (v) atuação em órgãos específicos. Embora os resultados tenham sido obtidos com animais, sugere-se precaução com os exames em medicina nuclear em pacientes que utilizem Hypericum perforatum como medicamento.

\section{Referências}

1- Shih WJ, Bognar B. Early appearance of the inferior vena cava in a Tc-99m red blood cell first-pass study: a sign of superior vena cava obstruction. Clin Nucl Méd 2000; 25:679-81.

2- Milhara Y, Kubota K, Nagata N, Takagi K, Morie T, Oda N, Ogura R, Watanabe Y, Terano A, Honma K. Total intraoperative enteroscopy using a colonoscope for detecting the bleeding point. Hepatogastroenterology, 2004; 51:1401-3.

3- Tsai CC, Yen TC, Tzen KY. The value of Tc-99m red blood cell SPECT in differentiating giant cavernous hemangioma of the liver from other liver solid masses. Clin Nucl Med 2002; 27: 578-81.

4- Sampson CB. Complications and difficulties in radiolabelling blood cells: a review. Nucl Med Commun, 1996; 17:648-58.

5- Reineger IW, Oliveira JF, Caldeira-De-Araújo A, Bernardo-Filho M. Effect of Peumus boldus on the labeling of red blood cells and plasma proteins with technetium-99m. Appl Radiat Isot, 1999; 51:145-9.

6- Oliveira JF, Braga ACS, Ávila ASR, Araújo AC, Cardoso VN, Bezerra RJAC, Bernardo-Filho M. Assessment of the effect of Maytenus ilicifolia (espinheira santa) extract on the labeling of red blood cells and plasma proteins with technetium-99m. J Ethnopharmacol 2000; 72:179-84.

7- Oliveira JF, Avila AS, Braga ACS, Oliveira MBN, Boasquevisque EM, Jales RL, Cardoso VN, Bernardo-Filho M. Effect of extract of medicinal plants on the labeling of blood elements with techentium99m and on the morphology of red bool cells: I - a study with Paullinia cupana. Fitoterapia 2002; 73:305-12.

8- Oliveira JF, Santos-Filho SD, Catanho MTJ, Srivastava SC, LimaFilho GL Bernardo-Filho M. Effect of extract of medicinal plant on the labeling of blood elements with technetium-99m and on the morphology of red blood cells (RBC): Toxicological action of roast coffee beans (Coffea arabica). Indian J Nucl Med 2003; 18:52-6.

9- Diré G, Lima E, Mattos D, Oliveira MB, Pereira MJ, Moreno S, Freitas R, Gomes ML, Bernardo-Filho M. Effect of chayotte (Sechium edule) extract on the biodistribution of technetium-99m and on the morphometry of red blood cells. J Labelled Comp Radiopharm 2001; 44:648-50.

10- Lima EA, Dire G, Mattos DM, Freitas RS, Gomes ML, Oliveira MB, Faria MV, Jales RL, Bernardo-Filho M. Effect of an extract of cauliflower (leaf) on the labeling of blood elements with technetium-99m and on the survival of Escherichia coli AB1157 submitted to the treatment with stannous chloride. Food Chem Toxicol 2002; 40: 9149-53.

11- Moreno SRF, Diré G, Freitas RS, Farah MB, Lima-Filho GL, Rocha EK, Jales RLC Bernardo-Filho M. Effect of Ginkgo biloba on the labeling of blood elements with technetium-99m: in vitro study. Rev Bras Farmacogn 2002; 12:62-3.

12- Moreno S, Rocha EK, Pereira M, Mandarim-Lacerda C, Freitas RS, Nascimento ALR, Carvalho JJ, Lima-Filho GL, Diré G, Lima EAC, Bernardo-Filho M. Ginkgo Biloba: Experimental model to evaluate it's action on the labeling of blood elements with technetium-99m and on the morphometry of red blood cells. Pakistan J Nut 2004; 3:68-71.

13- Santos-Filho SD, Diré GL, Lima E, Oliveira MN, BernardoFilho M. Effect of Mentha crispa (mint) extract on the labeling of blood elements with technetium-99m: A possible evaluation of free radicals. J Biol Sci 2004; 4: 266-70.

14- Early P J, Sodee DB. Principles and Practice of Nuclear Medicine. London: Mosby, 1995. 
15- Hladik III WB, Saha GB, Study KT. Essentials of Nuclear Medicine Science. Baltimore-London; Willians \& Wilkings, 1987.

16- Britto DMM, Gomes ML, Rodrigues PC, Paula EF, Gutfilen B, Bernardo-Filho M. Effect of a chemotherapeutic drug on the biodistribution of 99mTc-DTPA in Balb/c mice. J Exp Clin Cancer Res 1998; 17:313-6.

17- Spicer JA, Hladick WB, Mulberry WE. The effects of selected antineoplastic agents on the labeling of erythrocytes with technetium99m using the Ultra Tag RBC kit. J Nucl Med Technol 1999; 27:132-5.

18- Mattos DMM, Gomes ML, Freitas RS, Rodrigues PC, Nascimento VD, Boasquevisque EM, Paula EF, Bernardo-Filho M. Assessment of the vincristine on the biodistribution of $99 \mathrm{mTc}$ labelled glucoheptonic acid in female Balb/c mice. Nucl Med Commun 2000; 21:117-21.

19- Gomes ML, Oliveira MBN, Bernardo-Filho M. Drug Interaction with radiopharmaceuticals: Effect on the labeling of red blood cells with technetium-99m and on the bioavailability of radiopharmaceuticals. Braz Arch Biol Technol 2002; 45:143-9.
20- Ferreira SH, Barata LES, Salles SLM, Queiróz SRR, Neto NEH, Corazza R, Farias, RC Medicamentos a partir de plantas medicinais no Brasil. Rio de Janeiro: Academia Brasileira de Ciências, 1998.

21- Kumar V, Singh PN, Bhattacharya SK. Anti-stress activity of Indian Hypericum perforatum. Indian J Exp Biol 2001; 39:344-9.

22- Hesslewood S, Leung E. Drug interaction with radiopharmaceuticals. Eur J Nucl Med 1994; 21:348-56.

23- Gutfilen B, Boasquevisque EM, Bernardo-Filho M. Calcium channel blockers: interference on red blood cells and plasma proteins labeling with Tc-99m. Rev Esp Med Nucl 1992; 11:195-9.

24- Krishtal O, Lozovaya N, Fisunov A, Tsintsadze T, Pankratov Y, Kopanitsa M, Chatterjee SS. Modulation of ion channels in rat neurons by the constituents of Hypericum perforatum. Pharmacopsychiatry 2001;34:S74-82.

25- Neagoe I, Macri BM, Flonta ML. Hyperici herba extract interaction with artificial lipid bilayers. J Pharm Pharmacol 2004; $56: 1283-9$.

Santos-Filho SD, Bernardo-Filho M. Effect of Hypericum perforatum extract on in vitro labelling of blood elements with technetium-99m and on biodisponibility of sodium pertecnetate in Wistar rats. Acta Cir Bras [serial on line] Available from: URL: htt://www.scielo.br/acb.

ABSTRACT - Purpose: To evaluate the effect of a hiperico extract (Hypericum perforatum) on the labeling of blood elements with technetium-99m (99mTc) and in the bioavailability of the radiopharmaceutical sodium pertechnetate in Wistar rats. Methods: Blood (heparinized) withdrawn from Wistar rats is incubated with a hiperico extract, with a stannous cloride and with 99mTc, as sodium pertechnetate $(99 \mathrm{mTcO} \mathrm{Na})$. Plasma $(\mathrm{P})$ and cells $(\mathrm{C})$ are isolated by centrifugation. Samples of $\mathrm{P}$ and $\mathrm{C}$ are also precipitated with trichloroacetic acid (TCA 5\%) and soluble (FS-P; FS-C) and isoluble (FI-P; FI-C) fractions are separated. In the bioavailability analysis, the extract or $\mathrm{NaCl} 0.9 \%$ solution is administrated into Wistar rats (gavage) during 15 days. Sodium pertechnetate was administered and after $10 \mathrm{~min}$, the animals are sacrificed, the organs were isolated, the radioactivity determined in a well counter, and the percentages of radioactivity per gram $(\%$ ATI $/ g)$ in the organs are calculated. Results: The hiperico extract decreased significantly $(\mathrm{P}<0.05)$ the \%ATI in the cells, cellular insoluble fraction and plasma insoluble fraction. The biodistribution was significantly $(\mathrm{P}<0.01)$ decreased in bone, muscle and thyroid and significantly $(\mathrm{P}<0.05)$ increased in pancreas. Conclusion: The analysis of the results indicates that in studied extract should have substances that should oxidize the stannous ion, reducing the fixation of the 99mTc on the erythrocytes and plasma and cellular proteins. Moreover, it could produce metabolic alterations with influence in the uptake of the radiopharmaceutical $99 \mathrm{mTcO}_{4} \mathrm{Na}$ in bone, muscle, pancreas and thyroid.

KEYWORDS: Hiperico. Technetium-99m. Bioavailability. Surgery.

Correspondência:

Sebastião David Santos-Filho

Universidade do Estado do Rio de Janeiro

Instituto de Biologia Roberto Alcantara Gomes

Departamento de Biofísica e Biometria

Laboratório de Radiofarmácia Experimental

Av. 28 de Setembro, 87

20551-030. Rio de Janeiro - RJ

Tel.: 021-2587-6432

sdsfilho@terra.com.br

Conflito de interesse: nenhum

Fonte de financiamento: CNPq, FAPERJ, UFRN, UERJ 